\title{
EL DERECHO A LA SEGURIDAD SOCIAL DE LAS PERSONAS QUE REALIZAN TRABAJO NO REMUNERADO DEL HOGAR: ANÁLISIS DESDE EL ARTÍCULO 3o. DE LA RESOLUCIÓN NÚM. CD 513*
}

THE RIGHT TO SOCIAL SECURITY OF PEOPLE WHO PERFORM

UNPAID WORK AT HOME: ANALYSIS FROM ARTICLE 30. OF RESOLUTION No. CD 513

\author{
LE DROIT Â LA SÉCURITÉ SOCIALE POUR LES PERSONNES \\ QUI EFFECTUENT DES TRAVAUX MÉNAGERS NON RÉMUNÉRÉS: \\ ANALYSE DE L'ARTICLE 3o. DE RESOLUTION No. CD 513
}

\author{
María Claudia SÁNCHEZ VERA** \\ Seyedeh Sougand HessamzadeH Villamagua*** \\ Gustavo Marcelo SiLVA CAJAS****
}

\begin{abstract}
RESUMEN: El presente trabajo de investigación abordará con un enfoque crítico el derecho a la seguridad social de las personas que realizan trabajo no remunerado del hogar. $\mathrm{Al}$ respecto, es necesario tener presente que antes de la entrada en vigencia de la Constitución de la República del Ecuador, promulgada en octubre 2008, sólo se reconocía el derecho al trabajo a quienes prestaban sus servicios bajo relación de dependencia y el consiguiente derecho a la seguridad social.

A su vez, a partir de la vigencia de la Constitución de la República de 2008; se incorporó el reconocimiento de las labores de autosustento y cuidado humano que se realizan en los hogares como una forma de trabajo. Por ello, la Ley Orgánica para la Justicia Laboral y Reconocimiento
\end{abstract}

* Recibido el 5 de mayo de 2020 y aceptado para su publicación el 3 de septiembre de 2020.

** Docente de tiempo completo en la carrera de derecho e investigadora en la Universidad de Otavalo.

*** Docente de tiempo completo en la carrera de derecho e investigadora en la Universidad de Otavalo.

**** Docente de tiempo completo en la carrera de derecho e investigador en la Universidad de Otavalo.

Revista Latinoamericana de Derecho Social
Núm. 32, enero-junio de 2021, pp. 71-93 
del Trabajo en el Hogar, reformó a la antes referida Ley de Seguridad Social, incluyendo en el grupo de afiliados al Instituto Ecuatoriano de Seguridad Social (IESS), a las personas que realizan trabajo no remunerado del hogar. Sin embargo, lo que se cuestiona es que este sector de la población, a pesar de tener ante el sistema de seguridad social ecuatoriano la calidad de afiliadas, no están protegidas conforme lo dispone la normativa interna del IESS, ante un accidente de trabajo o una enfermedad profesional, situación que evidencia un reconocimiento limitado de su derecho a la seguridad social.

Palabras clave: seguridad social, Ecuador, contingencias, prestaciones, riesgos del trabajo.

ABSTRACT: This research work will address with a critical approach, the right to social security of people who do unpaid work from home. In this regard, it is necessary to keep in mind that before the entry into force of the Constitution of the Republic of Ecuador promulgated in October 2008; only the right to work was recognized, to those who provided their services under a dependency relationship and the consequent right to social security.

In turn, from the effective date of the Constitution of the Republic of 2008; the recognition of self-support and human care work carried out in homes as a form of work was incorporated. Therefore, the Organic Law for Labor Justice and Recognition of Work at Home reformed the aforementioned Social Security Law, including within the group of affiliates of the Ecuadorian Social Security Institute (IESS), to people who work unpaid household. However, what is questioned is that this sector of the population, despite having before the Ecuadorian social security system the quality of affiliates, are not protected as provided by internal regulations of the IESS, against an accident at work or a professional illness; situation that shows a limited recognition of their right to social security.

Keywords: Social Security, Ecuador, Contingencies, Benefits, Occupational Hazards.

RÉSUMÉ: Ce travail de recherche abordera avec une approche critique, le droit à la sécurité sociale des personnes qui effectuent un travail non rémunéré à domicile. À cet égard, il convient de garder à l'esprit qu'avant l'entrée en vigueur de la Constitution de la République de l'Équateur promulguée en octobre 2008; Seul le droit au travail est reconnu à ceux 
qui fournissent leurs services dans le cadre d'une relation de dépendance et le droit à la sécurité sociale qui en découle.

À son tour, à compter de la date d'entrée en vigueur de la Constitution de la République de 2008; La reconnaissance du travail d'auto-assistance et de soins humains effectué à domicile comme une forme de travail a été incorporée. Par conséquent, la loi organique pour la justice du travail et la reconnaissance du travail à domicile a réformé la loi sur la sécurité sociale susmentionnée, y compris au sein du groupe des affiliés de l'Institut équatorien de sécurité sociale (IESS), les personnes qui travaillent ménage non rémunéré. Cependant, ce qui est remis en cause, c'est que ce secteur de la population, bien qu'il ait devant le système équatorien de sécurité sociale la qualité des affiliés, n’est pas protégé comme le prévoit le règlement intérieur de l'IESS, contre un accident du travail ou un maladie professionnelle; situation qui montre une reconnaissance limitée de leur droit à la sécurité sociale.

Mots-clés: sécurité sociale, Équateur, éventualités, avantages sociaux, risques professionnels.

SumARIO: I. Introducción. II. Seguridad social: antecedentes históricos. III. Seguridad social: definición y reflexión crítica. IV. Seguridad social y seguro social: ¿son conceptos distintos? V. Naturaleza juridica de las cotizaciones al sistema de seguridad social. VI. Demografía y seguridad social: afiliados al Seguro General Obligatorio. VII. Riesgos cubiertos por el Seguro General Obligatorio. VIII. Riesgos del trabajo: análisis del artículo 30. del Reglamento del Seguro General de Riesgos del Trabajo.

IX. Conclusiones. X. Bibliografía.

\section{INTRODUCCIÓN}

\section{Objetivo}

a presente investigación tiene como finalidad demostrar que el sistema Lde seguridad social ecuatoriano (conjunto de instituciones, normativa, recursos humanos, económicos, etcétera), no es verdaderamente de cohorte universal, debido a que no respeta estrictamente uno de los principios rectores de la seguridad social, como es el principio de universalidad (conforme con el cual todos los afiliados deben estar protegidos en igualdad de condiciones frente a todas las contingencias que brinda el Seguro General Obligatorio 
a través del IESS y la Red Pública de Salud a sus afiliados), generando como resultado un limitado derecho a la seguridad social hacia las personas que realizan trabajo no remunerado del hogar.

\section{Metodología}

Documental, histórico y analítico crítico.

\section{Resultados}

El resultado principal de este estudio es el bajo número de población que ha optado por afiliarse al Instituto Ecuatoriano de Seguridad Social bajo la modalidad del trabajo no remunerado del hogar, una evidencia clara de la falta de confianza que tiene la ciudadanía en el sistema.

\section{Limitaciones del estudio}

Una restricción para el desarrollo de este estudio fue el estrecho bagaje teórico que en Latinoamérica, y de manera particular en Ecuador, existe en materia de seguridad social.

\section{Originalidad}

Tanto el tema como el enfoque desde el cual se aborda la presente investigación, son innovadores y originales.

\section{SEGURIDAD SOCIAL: ANTECEDENTES HISTÓRICOS}

$\mathrm{P}$ revio al estudio de lo que hoy se entiende como seguridad social, es necesario conocer su origen. En este contexto, José Mario Ruiz explica tres formas anteriores a ella. La primera es conocida como beneficencia o asistencia; aquella que "... se debió primero a la iniciativa privada especialmente familiar, profesional; posteriormente los poderes públicos toman una parte cada vez más preponderante... es un régimen que reconoce a una categoría de perso- 
nas el beneficio de los subsidios a expensas de la colectividad...". ${ }^{1}$ Dicho de otro modo, la seguridad social inició como una forma de iniciativa privada y luego pública de asistencia dirigida hacia personas de escasos recursos económicos, a quienes se les reconoce una serie de beneficios financiados por los aportes de quienes percibían mayores ingresos. En la asistencia es donde se evidencia con claridad el principio de solidaridad.

Como siguiente paso está el seguro, aquel que consiste en una

... forma técnicamente más perfecta de garantía. Puede ser garantía buscada libremente: seguro voluntario comercial, colectivo; se sirve de él sobre todo la clase media. Más frecuentemente es impuesta por la autoridad pública a las categorías moralmente incapaces de ahorro voluntario... entonces tenemos el seguro obligatorio. Voluntario u obligatorio, el seguro es un régimen, bajo el cual el beneficio de los subsidios está subordinado al pago de cotizaciones por sí mismo o por medio de otros... ${ }^{2}$

Además, es útil recalcar una idea, y es que el seguro en su expresión más frecuente es obligado por el Estado, a quienes de por sí no tienen esa cultura de previsión para el futuro. Es más, el beneficio de los subsidios está condicionado al pago de las cotizaciones (cabe recalcar que por primera vez surge este término) por sí mismo (sucede en lo que hoy se conoce como afiliación voluntaria) o por medio de otros (se presenta en la afiliación del trabajador bajo relación de dependencia, en la cual los aportes: tanto personal como patronal, cancela el empleador).

Por último, están presentes elementos de la garantía social moderna, aquella que tiene como punto de partida, la

"Social Security Act" de EE. UU. del 14 de agosto de 1935, [el cual] es el primer texto legislativo que introduce el término "seguridad social"... El Estado liberal cede en parte ante el "Welfare State". Se impone un seguro obligatorio. Hay un esfuerzo de coordinación; por vez primera se discute, en ocasión de esta ley, de la provisión universal de un mínimo de existencia, de la solidaridad entre las diversas clases de la nación. ${ }^{3}$

1 Ruiz, José Mario, La formación del concepto de seguridad social, Quito, Casa de la Cultura Ecuatoriana, 1961, p. 17.

2 Ibidem, pp. 17 y 18.

3 Ibidem, pp. 20 y 21. 
Para finalizar el escalón, está el Social Security Act, una ley federal aprobada en los Estados Unidos de América, el 14 de agosto de 1935. Éste fue un primer texto que hace referencia a la seguridad social, imponiendo a la población un seguro obligatorio. Además, con base en esta ley, se establecieron por primera vez mecanismos de cooperación o solidaridad entre toda la nación (sin importar sus clases).

\section{SEGURIDAD SOCIAL: DEFINICIÓN Y REFLEXIÓN CRÍTICA}

$\mathrm{P}$ ara empezar, es imprescindible conceptualizar un término medular, cuya comprensión facilitará la lectura crítica del presente trabajo. En este contexto, el Centro Interdisciplinario de Estudios sobre el Desarrollo Latinoamericano (CIEDLA), define a la seguridad social como

... el sistema legal de seguros sociales que otorga prestaciones en dinero, especie o servicios a la población protegida, para cubrirla [frente a] contingencias sociales que le provocan una reducción o pérdida en sus niveles de ingresos presentes o futuros y/o una carga económica suplementaria transitoria a permanente... ${ }^{4}$

Ahora bien, al efectuar una lectura detenida del párrafo anterior, se puede observar, entre otros aspectos, que este Centro de investigación ubica la conceptualización de la seguridad social dentro del derecho laboral, como es la seguridad social, desde una visión privatista, considerándola un sistema de seguros sociales.

Angélica Porras define a la seguridad social como "... un derecho bumano, ${ }^{5}$ que tiene como fin proteger a todas las personas frente a las contingencias de la

4 Centro Interdisciplinario de Estudios sobre el Desarrollo Latinoamericano, La seguridad social en Latinoamérica: un estudio comparativo del seguro social en Argentina y Colombia, Buenos Aires, CIEDLA, 1989, p. 21.

5 Con derechos humanos se hace referencia al "[conjunto] de facultades, prerrogativas, libertades y pretensiones de carácter civil, político, económico, social y cultural, incluidos los recursos y mecanismos de garantía de todas ellas, que se reconocen al ser humano, considerado individual y colectivamente". Véase Rodríguez y Rodríguez, Jesús y Carbonell, Miguel, voz: "Derechos humanos", Diccionario de derecho constitucional, 3a. ed., México, Porrúa-UNAM, 2009, p. 481. 
vida, derivadas de la falta de ingresos producidos por enfermedad, incapacidad, invalidez, vejez, desempleo o muerte...". ${ }^{6}$

En primer lugar, es básico tener en cuenta que existe una diferencia técnica entre los términos prestaciones ${ }^{7}$ y contingencia. Dentro de esta línea, por un lado, cuando se hace alusión a las necesidades, riesgos, percances, etcétera, que todo individuo puede sufrir en el transcurso de su existencia, se habla de contingencias. En este sentido, frente a aquellos inconvenientes están las herramientas que permiten de alguna manera apaciguar sus efectos nocivos. Para explicar mejor, y cerrando esta idea, la enfermedad, la muerte, el desempleo son contingencias; mientras que la atención médica, la hospitalización, la cirugía, la entrega de medicamentos, el auxilio de funerales, el montepío o el seguro de desempleo, son las prestaciones. ${ }^{8}$

Es, entonces, la seguridad social un derecho, prerrogativa o facultad, que tiene como finalidad amparar a la población afiliada al sistema de seguridad social cuya entidad legal y constitucionalmente responsable de brindar las prestaciones del seguro general obligatorio a los afiliados, es el Instituto Ecuatoriano de Seguridad Social; ${ }^{9}$ lo cual no resta la presencia de regímenes especiales, como el Seguro Social Campesino y otros cubiertos por el Instituto de Seguridad Social de las Fuerzas Armadas (ISSFA) y el Instituto de la Seguridad Social de la Policía Nacional (ISPOL) frente a las necesidades que se presenten a lo largo de su vida.

En concordancia con lo indicado, la Constitución de la República del Ecuador, vigente en el artículo 370, dispone que:

6 Porras Velasco, Angélica, "La seguridad social en Ecuador: un necesario cambio de paradigmas”, Foro Revista de Derecho, Ecuador, núm. 24, 2015, p. 91. Énfasis añadido.

7 Se dice que son el "[conjunto] de beneficios de orden social, laboral, económico... que otorga el Estado, entidades públicas, de servicio o privadas, sea en el cumplimiento de sus fines específicos, por mandato de ley o por acuerdo entre las partes". Véase Patiño Ledesma, Rodrigo y Pozo, Teodoro, Léxico jurídico tributario, Quito, CLD, 1996, p. 166.

8 Sobre el carácter prestacional de la seguridad social, se ha dicho que dicho “... contenido obligacional consiste en dar o en hacer bienes o servicios que, en principio, el sujeto titular podría obtener en el mercado si tuviera los medios suficientes para ello". Véase Prieto Sanchís, Luis, "Los derechos sociales y el principio de igualdad sustancial", en Caicedo Tapia, Danilo y Porras Velasco, Angélica (eds.), Igualdady no discriminación: el reto de la diversidad, Quito, Ministerio de Justicia, Derechos Humanos y Cultos, 2010, p. 108.

9 Como un dato adicional y de carácter trascendente, se debe conocer que "mediante Decreto Supremo núm. 40, de 2 de julio de 1970 y publicado en el Registro Oficial núm. 15, de 10 de julio del mismo año, se transformó la Caja Nacional del Seguro Social en el Instituto Ecuatoriano de Seguridad Social”. Véase Instituto Ecuatoriano de Seguridad Social, Manual para afiliados y empleadores del Instituto Ecuatoriano de Seguridad Social, Quito, IESS, 1984, p. 4. 
El Instituto Ecuatoriano de Seguridad Social, entidad autónoma regulada por la ley, será responsable de la prestación de las contingencias del seguro universal obligatorio a sus afiliados. La Policía Nacional y las Fuerzas Armadas podrán contar con un régimen especial de seguridad social, de acuerdo con la ley; sus entidades de seguridad social formarán parte de la red pública integral de salud y del sistema de seguridad social. ${ }^{10}$

Es más, el Instituto Ecuatoriano de Seguridad Social, es una entidad del servicio público, que goza de autonomía ${ }^{11}$ administrativa (el manejo de sus fondos y recursos serán de exclusiva responsabilidad del IESS, y por prohibición legal ninguna institución del Estado podrá intervenir en su administración ni peor aún menoscabar su patrimonio), ${ }^{12}$ financiera; inclusive se debe tener presente que tiene patrimonio propio, en virtud de que su presupuesto no forma parte del Presupuesto General del Estado.

Siguiendo con el hilo conductor de esta reflexión académica, con relación a la postura sostenida por Angélica Porras respecto de la seguridad social, es imprescindible resaltar su total fortaleza y aplicación en el Ecuador, debido a que el argumento tiene un vínculo muy fuerte con el modelo de Estado actual, que tal como lo indica la Constitución de la República del Ecuador de 2008,13 en el artículo 1o., corresponde a "... un Estado constitucional de derechos y justicia...". 14

10 Constitución de la República del Ecuador, Registro Oficial 449, 20 de octubre de 2008, artículo 370 .

11 La Ley de Seguridad Social con respecto a la naturaleza jurídica del Instituto Ecuatoriano de Seguridad Social, señala que "[el]Instituto Ecuatoriano de Seguridad Social [IESS]es una entidad pública descentralizada, creada por la Constitución Política de la República, dotada de autonomía normativa, técnica, administrativa, financiera y presupuestaria, con personería jurídica y patrimonio propio, que tiene por objeto indelegable la prestación del Seguro General Obligatorio en todo el territorio nacional". Véase Ley de Seguridad Social (Ecuador), Registro Oficial 465, Suplemento, 30 de noviembre de 2001, artículo 16.

12 Con respecto a los recursos del Instituto Ecuatoriano de Seguridad Social, la Constitución Política de la República, en su tiempo se pronunció en el sentido de que éstos son "propios y distintos de los del Estado, y servirán para cumplir adecuadamente los fines de su creación y funciones. Ninguna institución del Estado podrá intervenir en sus fondos y reservas ni afectar su patrimonio...". Véase Constitución Política de la República del Ecuador, Registro Oficial 1, 11 de agosto de 1998, artículo 59

13 Ecuador, op. cit.

14 Idem., artículo 1o. Énfasis añadido. 
Acerca de la esencia del Estado constitucional de derechos y justicia ${ }^{15}$, Ramiro Ávila Santamaría indica que:

[el] Estado de derecho se caracterizó, aunque suene tautológico, por el sometimiento del Estado al derecho, entendiendo al derecho como el conjunto de normas válidas formalmente... Sobra decir que la comprensión del derecho se restringe a la ley y, por tanto, a la producción legislativa. [No obstante, en] el Estado de derechos los puntos de referencia y análisis cambian profundamente. Por un lado, 1. El Estado; y 2. El derecho del que de éste emana están sometidos a los derechos de las personas y las colectividades... ${ }^{16}$

Del citado criterio se desprende entonces, esta evolución del Estado de derecho al constitucional de derechos y justicia (en el primero el Estado se somete al derecho desde una perspectiva puramente formalista. En definitiva, lo que no estaba presente, simplemente no existía para el derecho, o el Estado; mientras que en el segundo los derechos y la justicia someten al derecho, por lo tanto, todo aquello que se vincula con el núcleo esencial de los derechos se constituye en elementos de sometimiento del Estado desde una perspectiva neo constitucionalista).

En correspondencia con lo indicado, la seguridad social es un derecho fundamental ${ }^{17}$ reconocido tanto en la Constitución de la República del Ecuador, ${ }^{18}$

15 En este sentido, la doctrina manifiesta que "[el] Estado constitucional es el resultado de la evolución del Estado legal. El Estado legal se basa en el principio de legalidad, por el que todo acto del poder sólo puede hacer lo determinado en la ley... El Estado constitucional, en cambio, se basa en que los actos públicos y privados están sometidos a la Constitución, incluso la ley...". Véase en: Ávila Santamaría, Ramiro, "Caracterización de la Constitución de 2008: Visión panorámica de la Constitución a partir del Estado constitucional de derechos y justicia", en Andrade, Santiago et al. (eds.), La nueva Constitución del Ecuador: Estado, derechos e instituciones, Quito, Universidad Andina Simón Bolívar-Corporación Editora Nacional, 2009, p. 406.

16 Ibidem, pp. 408 y 409.

17 Dícese del término derechos fundamentales, "se ha hecho hincapié en la propensión doctrinal y normativa de reservar el término «derechos fundamentales» para designar los derechos positivados a nivel interno". Véase Pérez Luño, Antonio, Los derechos fundamentales, Madrid, Tecnos, 1986, p. 44.

18 "El derecho a la seguridad social es un derecho irrenunciable de todas las personas, y será deber y responsabilidad primordial del Estado. La seguridad social se regirá por los principios de solidaridad, obligatoriedad, universalidad, equidad, eficiencia, subsidiaridad, suficiencia, transparencia y participación, para la atención de las necesidades individuales y colectivas...". Véase Ecuador, op. cit., artículo 34. 
como en varios tratados internacionales de derechos humanos ratificados por el Estado ecuatoriano.

No obstante, siempre es enriquecedor nutrirse de visiones y criterios distintos. Al respecto de la esencia de la seguridad social como un derecho fundamental, desde la realidad colombiana, Rafael Rodríguez Mesa, ilustra este documento con la idea de que “... desde la [sentencia] T-561 de 1992 la Corte Constitucional considera como derecho fundamental la seguridad social cuando su no reconocimiento quebranta derechos fundamentales...". ${ }^{19}$ Dicho de otro modo, queda claro que para el país vecino, conforme al precedente sentado por la Corte Constitucional, el atribuir la característica de fundamental al derecho a la seguridad social está condicionado a la vulneración de otros derechos que sí están revestidos de tal calidad.

\section{SEGURIDAD SOCIAL Y SEGURO SOCIAL: ¿SON CONCEPTOS DISTINTOS?}

S eguridad social no es lo mismo que seguro social; ambos conceptos son básicos para la exploración crítica acerca de temas actualmente coyunturales dentro de tan indispensable área del conocimiento. Por una parte, ha quedado sumamente claro que la seguridad social es un derecho, mientras que el seguro social es una herramienta prevista por el Estado con la finalidad de cristalizar o materializar este derecho constitucional; el cual se analizó de manera profunda al inicio de este ensayo. En suma, el seguro social es el mecanismo que permite materializar y garantizar el derecho.

Antes de continuar, se debe tomar en consideración que todo derecho se vuelve en la práctica viable con la utilización de recursos económicos; mismos que en el caso del sistema de seguridad social ecuatoriano provienen tanto del Estado a través de los impuestos y otros medios para captar recursos públicos, como de los aportes de la ciudadanía en general; estando ésta conformada, por empleadores, trabajadores, afiliados voluntarios, ecuatorianos que residen en el exterior, afiliados independientes que poseen el Registro Único de Contribuyentes (RUC) o el Régimen Impositivo Simplificado (RISE). Lo indicado responde a la obligación que tienen los ciudadanos de cooperar con la seguridad social.

19 Rodríguez Mesa, Rafael, Estudios sobre seguridad social, Barranquilla, Universidad del Norte-Grupo Editorial Ibáñez, 2012, pp. 55 y 56. 
De conformidad con lo expresado, la Constitución en el numeral 15 de su artículo 83, considera como uno de los deberes y responsabilidades de los ecuatorianos, la de “... cooperar con el Estado y la comunidad en la seguridad social, y pagar los tributos establecidos por la ley....". ${ }^{20}$ Una vez leída la disposición constitucional, es posible caer en cuenta de que hay una contradicción semántica, en virtud de que la acción de cooperar, es por esencia voluntaria, mientras que pagar los aportes al Instituto Ecuatoriano de Seguridad Social, y los impuestos, son de carácter obligatorio. En este sentido, en lugar de cooperar debería estar el término contribución, ${ }^{21}$ que está acorde con la intención que tuvo la Asamblea Nacional Constituyente al redactar el citado artículo.

En este punto avanzado de la discusión, surge entonces una pregunta: ¿el sistema de seguridad social tiene un vínculo irrompible con el trabajo? Con respecto a esta interrogante, Marco Proaño Maya sostiene que "[el sistema del seguro social] surge de una relación de dependencia laboral, por la que el trabajador y el empleador asumen obligaciones y derechos...". ${ }^{22}$ Es totalmente evidente que la definición aportada por el autor ecuatoriano no es compatible con el principio de universalidad, ${ }^{23}$ uno de los principios rectores de la seguridad social, en razón de que se limita el ámbito de protección del seguro social, dirigiéndolo únicamente hacia quienes presten servicios bajo relación de dependencia, quedando entonces las demás personas desprotegidas y, sin acceso a la seguridad social, siendo éste un derecho humano, que se le debe reconocer a toda persona sin importar su condición laboral.

En ese sentido, ¿es el sistema de seguridad social realmente universal?, o simplemente el principio de universalidad queda como una retórica agradable en la Constitución de la República del 2008, recalcando nuevamente que el Ecuador es un Estado constitucional de derechos.

\footnotetext{
20 Ecuador, op. cit., artículo 83.
}

21 "Es la aportación económica determinada por leyes fiscales que hacen las personas naturales o jurídicas, nacionales o [extranjeras] que residan en el país, para satisfacer la atención de los servicios públicos del Estado...". Véase Patiño y Pozo, op. cit., p. 56.

22 Proaño Maya, Marco, Seguridad social y sociedad democrática, Quito, Editorial Americana, 2014, p. 89. Énfasis añadido.

23 La universalidad como principio, “... consiste en amparar a todos los seres humanos, sin excepción, como integrantes de la comunidad, quienes tienen derecho a la protección desde su nacimiento hasta su muerte. Busca la cobertura de todos los riesgos y contingencias sociales para toda la población...". Véase Rodríguez, Rafael, op. cit., p. 39. 


\section{NATURALEZA JURÍDICA DE LAS COTIZACIONES AL SISTEMA} DE SEGURIDAD SOCIAL

1 manera de inicio, el conocido profesor Fernando Pérez Royo, como un que “... las cotizaciones participan de las notas o caracteres esenciales que distinguen a los tributos: son prestaciones coactivas, impuestas unilateralmente por el Estado y su destino es la financiación de necesidades colectivas...". ${ }^{24}$ En otras palabras, la cantidad de dinero que mes a mes aportan los individuos al sistema de seguridad social, con el fin de estar protegidos frente a cualesquier contingencia que se presente, conforme lo explica el autor, son parte o tienen características similares a los tributos, siendo éstos: impuestos, tasas y contribuciones especiales de mejoras, los cuales estarán reservados únicamente para cubrir la demanda de la sociedad en materia de derechos.

Es más, Pérez Royo resalta la idea de que esta contribución es por esencia coactiva; vía que precisamente aplica la institución responsable del Seguro General Obligatorio para exigir el cumplimiento del pago de los aportes al sistema de seguridad social. En consecuencia, si el empleador conforme lo dispone la norma especializada en la materia, como es la Ley de Seguridad Social, no cancela dentro de quince días posteriores al mes correspondientes al aporte, el porcentaje que por ley le corresponde, ${ }^{25}$ se le considerará en mora, sin dejar atrás la responsabilidad patronal que se le atribuya.

En relación con el aspecto que se discute, Giuliani Fonrouge defiende una postura diferente, y es que

... se trata de una contribución especial, tanto en la parte patronal como en la de obreros y empleados, por entender que se dan las condiciones que caracterizan esa categoría jurídico-financiera según la definimos anteriormente. Hay un beneficio indudable para unos y otros en la organización de la

24 Pérez Royo, Fernando, "Ingresos tributarios de la seguridad social", Curso de derecho tributario parte especial. El sistema tributario: los tributos en particular, Madrid, Marcial Pons, Ediciones Jurídicas y Sociales, 2002, p. 839.

25 Es aquí donde es indispensable dejar claro que conforme se desprende del anexo 2 del Reglamento para la aplicación de la Cesantía y Seguro de Desempleo, el porcentaje que aporta el trabajador y el empleador varía dependiendo de si el sector es público o privado. En el caso de que éste sea privado, el afiliado contribuirá con el $9.45 \%$, y el empleador con el $11.15 \%$. 
previsión y de la asistencia [social]; más visible en el caso de los empleados, pero no menos real en el de los patronos. ${ }^{26}$

En definitiva, el acto de cotizar al sistema de seguridad social, de acuerdo con Fonrouge, es una contribución especial, ya que lleva consigo beneficios a largo plazo para ambas partes de la relación laboral. Por una parte, el empleador cumplirá con una obligación legal y evitará las respectivas sanciones pecuniarias por su incumplimiento. Por otra parte, el trabajador obtendrá beneficios en razón del acceso a todas las prestaciones del Seguro General Obligatorio.

Concordando con el criterio sostenido por Giuliani Fonrouge, las contribuciones especiales son una parte del gran universo de los tributos, y por su esencia beneficiosa para ambas partes, se alinea más a la realidad de las cotizaciones al sistema de seguridad social.

\section{DEMOGRAFÍA Y SEGURIDAD SOCIAL: AFILIADOS AL SEGURO GENERAL OBLIGATORIO}

$\mathrm{V}$ ale la pena resaltar que la demografía como ciencia es muy importante para comprender y estudiar la seguridad social; teniendo presente que por demografía se entiende “... el estudio estadístico de las poblaciones, particularmente por lo que respecta a su tamaño y densidad, a su distribución y a la estadística vital...". ${ }^{27}$ En esta línea, el Instituto Ecuatoriano de Seguridad Social, en el caso del Ecuador, y los sistemas de seguridad social a lo largo del mundo se nutren de esta rama del conocimiento humano, debido a que factores como el número de habitantes, la edad, la situación socioeconómica, la condición laboral, etcétera, influyen a la hora de diseñar los distintos modelos de afiliación, el porcentaje de cotización, los requisitos, las prohibiciones, el costo para la institución, etcétera.

En concordancia con lo señalado en el párrafo anterior, se pronuncia Myres, quien señala:

[es] evidente que en el sistema de seguridad social ha de influir sobremanera la estructura demográfica del país o de la población amparada. Esto es

26 Giuliani Fonrouge, Carlos, Derecho financiero, 3a. ed., Buenos Aires, Depalma, 1984, p. 948.

27 Myers, Robert, "Demografía y seguridad social", Seguridad social y población, Washington, OEA, 1969, p. 3. 
así tanto desde el punto de vista de la clase del programa necesario como de su costo [que a su vez puede influir en la viabilidad de adoptar varias disposiciones, por razón de los recursos financieros disponibles que son necesariamente limitados]. ${ }^{28}$

En suma, la seguridad social tiene un nexo muy sólido con la demografía; toda vez que el núcleo de ésta es la población; los factores que con anterioridad se indicaron, influyen en la distribución del presupuesto del sistema de seguridad social hacia las distintas modalidades de afiliación.

En lo que a la realidad ecuatoriana respecta, la Ley de Seguridad Social en su artículo 2o.; con respecto a los afiliados al Seguro General Obligatorio, ${ }^{29}$ expresa que:

... a. El trabajador en relación de dependencia; b. El trabajador autónomo; c. El profesional en libre ejercicio; d. El administrador o patrono de un negocio; e. El dueño de una empresa unipersonal; f. El menor trabajador independiente; y, g. Los demás asegurados obligados al régimen del Seguro General Obligatorio en virtud de leyes y decretos especiales. ${ }^{30}$

En otras palabras, conforme lo manifiesta la ley de la materia, estarán protegidos y podrán acceder a las distintas prestaciones dependiendo de la modalidad de afiliación a la que se acoja el ciudadano-afiliado; los trabajadores (quienes presten sus servicios lícitos y personales a su empleador; pudiendo tratarse de una persona natural o jurídica, bajo relación de dependencia, en este caso, son los empleadores quienes deben ingresar a sus trabajadores al IESS, a través de un aviso de entrada), el profesional en libre ejercicio (médico, abogado, etcétera), quien administre o sea dueño de un negocio (sin importar la actividad de la que se trate), el trabajador cuya edad sea menor a los 18 años, etcétera.

\section{Idem.}

29 Un dato relevante es que, a partir del 16 de febrero del 2005, gracias al pronunciamiento del Tribunal Constitucional, la frase obligados a solicitar la protección fue declarada inconstitucional por ser contraria a lo dispuesto por el tercer inciso del artículo 57 de la Constitución Política de la República del Ecuador, debido a que la solicitud no es un requisito obligatorio para que el individuo se beneficie de la protección de la seguridad social. Además, al ser la seguridad social un derecho irrenunciable, sería ilógico y contradictorio que se obligue a solicitar un derecho de esta naturaleza. Véase Ecuador, Tribunal Constitucional, "Resolución", en Casos acumulados núm. 052 y núm. 054-2001-TC, 14 de febrero del 2005, p. 7.

30 Ecuador, op. cit., artículo 2o. 
No obstante, la citada norma no es de carácter taxativo, lo cual quiere decir que quienes constan en el artículo 2o. de la Ley de Seguridad Social, no son los únicos que ostentan la calidad de afiliados. En este sentido, se incluyen a quienes no prestan sus servicios o ejercen una actividad bajo relación de dependencia y solicitan de manera voluntaria su afiliación al sistema de seguridad social.

Cabe recalcar además que al ser considerada la seguridad social como un derecho humano, “... legalmente, ya no se debería, por lo tanto, hacer derivar el derecho a la seguridad social sólo de la condición de ser trabajador o de pagar determinadas cotizaciones...". ${ }^{31}$ Dicho de otro modo, en la actualidad, en un Estado donde lo primordial son los derechos de las personas, es absurdo e ilógico que todavía se niegue o prive del acceso y goce de un derecho fundamental como es la seguridad social.

En concordancia con esta idea, y en respuesta a lo dispuesto por la Constitución de la República, ${ }^{32}$ en el Ecuador el 20 de abril de 2015 entró en vigor la Ley Orgánica para la Justicia Laboral y Reconocimiento del Trabajo en el Hogar; ${ }^{33}$ aquella que reforma la Ley de Seguridad Social. En este sentido, el artículo 66 de dicha Ley Orgánica, dispone que se “... 1. [Sustituya] el texto de la letra g) del artículo 2o. por el siguiente: «g. Las personas que realicen trabajo del hogar no remunerado»...", 34 en otras palabras, tomando en consideración a la universalidad como principio rector de la seguridad social, incluye en el grupo de afiliados a las personas que realizan labores de autosustento y cuidado humano en los hogares, como el aseo del hogar, el cuidado y alimentación de los hijos y del entorno familiar en general.

Antes de continuar con el análisis, se debe conceptualizar el término persona que realiza trabajo no remunerado del hogar, para ello, el artículo 64 de la Resolución núm. CD 516 (Reglamento de Aseguramiento, Recaudación y Gestión de Cartera del Instituto Ecuatoriano de Seguridad Social), se encarga de dar una respuesta, y dice que “... es aquella que desarrolla de manera exclusiva tareas de cuidado del hogar sin percibir remuneración o compensación económica

\footnotetext{
31 Rendón Vásquez, Jorge, Derecho de la seguridad social, Lima, Grijley, 2008, p. 102.

32 "El Estado garantizará y hará efectivo el ejercicio pleno del derecho a la seguridad social, que incluye a las personas que realizan trabajo no remunerado en los hogares, actividades para el autosustento en el campo, toda forma de trabajo autónomo y a quienes se encuentran en situación de desempleo". Véase Ecuador, op. cit., artículo 34. Énfasis añadido.

33 Ecuador, Ley Orgánica para la Justicia Laboral y Reconocimiento del Trabajo en el Hogar, Registro Oficial 483, Tercer Suplemento, 20 de abril de 2015.

34 Ibidem, artículo 66.
} 
alguna...". ${ }^{35}$ Es más, en aquella época el gobierno de turno hizo mediante un estudio técnico, ${ }^{36}$ una proyección del número de afiliados bajo el trabajo no remunerado del hogar, y por medio de un estudio técnico calculó que en 2015, el IESS registraría un total de 1’247,115 y en 2018 la cifra ascendería a 1’315,961 (afiliados bajo el trabajo no remunerado del hogar). Sin embargo, a continuación se observará que aun en 2020, el número de personas afiliadas bajo el trabajo no remunerado del hogar es muy bajo en comparación con la proyección que se desprende del estudio actuarial realizado por el IESS.

TABLA 1. Total de la población afiliada al Instituto Ecuatoriano de Seguridad Social

\begin{tabular}{|l|c|}
\hline & Afiliados (núm.) \\
\hline Sector público & 645,823 \\
\hline Sector privado & 2 ’015,375 \\
\hline Independientes & 259,879 \\
\hline Semicontributivo & 235,787 \\
\hline Pasantes sector público & 9,908 \\
\hline Pasantes sector privado & 6,286 \\
\hline Voluntarios en el Ecuador & 164,058 \\
\hline Voluntarios en el exterior & 15,128 \\
\hline Voluntarios puros & 98 \\
\hline Total & $3 ’ 352,342$ \\
\hline
\end{tabular}

FUENTE: elaboración propia con datos de la Subdirección Nacional de Afiliación, Cobertura y Gestión de la Información del IESS.

En concordancia, conforme se demuestra con datos oficiales aportados por la misma institución responsable de la seguridad social en el Ecuador, por medio del departamento competente, las cifras a nivel nacional, en cuanto al trabajo no remunerado del hogar, ascienden únicamente a: 235,787 afiliados

35 Ecuador, Resolución núm. C.D. 516. Registro Oficial 687, Edición Especial, 15 de agosto de 2016, artículo 66.

36 Ecuador, Instituto Ecuatoriano de Seguridad Social, Valuación financiera actuarial para la protección del seguro general obligatorio a las personas que realicen trabajo en el hogar no remunerado, Quito, IESS, 2015, p. 40. 
bajo el régimen semicontributivo; en otras palabras, personas que realizan trabajo no remunerado del hogar). Es más: sector privado, público, independientes, semicontributivos, pasantes, voluntarios en el exterior, voluntarios en el Ecuador, el Instituto Ecuatoriano de Seguridad Social cuenta con un total de 3’352,342 afiliados, cifra que evidentemente está muy por debajo de la meta que se propusieron las autoridades de la institución. Lo cual es una evidencia clara de las huellas negativas que ha dejado el actuar de las autoridades públicas en la ciudadanía, generando una desconfianza en el sistema de seguridad social en su eficacia, calidad, universalidad, igualdad, etcétera.

\title{
VII. RIESGOS CUBIERTOS POR EL SEGURO GENERAL OBLIGATORIO
}

\begin{abstract}
A manera de inicio, y partiendo de que ha quedado clara la diferencia - 1 entre prestaciones y contingencias, la Ley de Seguridad Social en el artículo 3o., al respecto de las contingencias, dispone que:
\end{abstract}

[el] Seguro General Obligatorio protegerá a las personas afiliadas, en las condiciones establecidas en la presente Ley y demás normativa aplicable, de acuerdo con las características de la actividad realizada, en casos de: a. Enfermedad; b. Maternidad; c. Riesgos del trabajo; d. Vejez, muerte, e invalidez, que incluye discapacidad; y, e. Cesantía. f. Seguro de Desempleo. ${ }^{37}$

En definitiva, el Seguro General Obligatorio, a través de instituciones del sector público como el Instituto Ecuatoriano de Seguridad Social, y en lo que a salud concierne: hospitales y dispensarios del IESS, y la Red Pública Integral (Ministerio de Salud Pública), cumplen con la población afiliada y sus familias (cónyuge e hijos menores de 18 años). Sin embargo, es necesario indicar que los ciudadanos registrados en el sistema de seguridad social en calidad de afiliados están amparados frente al desempleo desde el 28 de marzo del 2016, fecha en la cual entró en vigor la Ley Orgánica para la Promoción del Trabajo Juvenil, Regulación Excepcional de la Jornada de Trabajo, Cesantía y Seguro de Desempleo, ${ }^{38}$ reformando el citado artículo 3o. de la Ley de Seguridad Social.

\footnotetext{
37 Ecuador, op. cit., artículo 3o. Énfasis añadido.
}

38 En este contexto, en el referido cuerpo legal, se manifiesta que el "Artículo. Del seguro de desempleo. El seguro de desempleo es la protección económica que protege a los afiliados 


\section{RIESGOS DEL TRABAJO: ANÁLISIS DEL ARTÍCULO 3 O. DEL REgLAMENTO DEL SEguro GENERAL DE RIESGOS DEL TRABAJO}

$\mathrm{P}$ ara empezar, el 12 de julio del 2016, el IESS, a través de su máximo órgano de gobierno, el Consejo Directivo, aprobó la Resolución núm. C.D. 513 (Reglamento del Seguro General de Riesgos del Trabajo), ${ }^{39}$ normativa interna que regula todo lo concerniente a los infortunios laborales como: "Accidente de trabajo"40 (acontecimiento que se presenta de manera imprevista en la carrera productiva del afiliado) y "Enfermedad profesional", ${ }^{41}$ en lo referente a las prestaciones a las cuales tienen derecho los afiliados que han sido víctimas del siniestro laboral, requisitos de acceso, quienes son considerados legalmente sujetos protegidos, tipos de incapacidades y su respectiva valoración, etcétera. Sin embargo, los empleadores: personas naturales y personas jurídicas (tanto públicas como privadas), deben poner en práctica una política de prevención de riesgos laborales, dotando a los trabajadores de insumos como guantes, mascarillas, botas, tapones para los oídos, etcétera.

No obstante, es imprescindible dejar claro que existe un criterio diferenciador entre los dos conceptos medulares, que son el accidente de trabajo

del Instituto Ecuatoriano de Seguridad Social, bajo relación de dependencia por la pérdida de ingresos generada por un cese temporal de actividades productivas por causas ajenas a su voluntad y se regirá por los principios de obligatoriedad, suficiencia, integración, solidaridad y subsidiariedad”. Véase Ecuador, Ley Orgánica para la Promoción del Trabajo Juvenil, Regulación Excepcional de la Jornada de Trabajo, Cesantía y Seguro de Desempleo. Registro Oficial 720, 28 de marzo del 2016, artículo 6o.

39 Con la finalidad de adaptarse a la esencia protectora y garantista de la Constitución de la República, el numeral 5 del artículo 326, expresa que "[el] derecho al trabajo se sustenta en los siguientes principios: 5 . Toda persona tendrá derecho a desarrollar sus labores en un ambiente adecuado y propicio, que garantice su salud, integridad, seguridad, higiene y bienestar". Véase Ecuador, op. cit., artículo 326 núm. 5.

40 Dícese, de “... cualquier suceso anormal que se presenta de forma brusca e inesperada, normalmente evitable, que interrumpe la continuidad del trabajo, pudiendo causar o no lesiones a las personas y genera pérdidas económicas...”. Véase Goñalons Benavent, Anna, "Patología del trabajo", en Moreno Cáliz, Susana (coord.), Manual de prevención de riesgos laborales (seguridad, bigiene y salud en el trabajo), Barcelona, Atelier-Librería Jurídica Cevallos, 2012, p. 422.

41 Se entiende que con este término se hace referencia cuando “... la relación causal está reconocida legalmente, y de enfermedades relacionadas con el trabajo cuando hay evidencias científicas de esta relación causal, pero no son reconocidas legalmente...". Véase Benavides, Fernando et al., "Trabajo y salud", Salud laboral. Conceptos y técnicas para la prevención de riesgos laborales, Barcelona, Elsevier-Masson, 2007, p. 38. 
y una enfermedad profesional; criterio al cual la doctrina especializada en materia de medicina del trabajo, lo conoce como periodo de latenciat2 (tiempo que transcurre hasta que se presenten los efectos nocivos en el organismo del individuo que sufre el siniestro laboral). En este sentido, el tiempo es menor en el accidente de trabajo (casi inmediato); mientras que en la enfermedad profesional se hace evidente la sintomatología en un periodo mucho mayor; factor que complica mucho más la tarea de los médicos ocupacionales de las distintas direcciones provinciales del IESS, al establecer la relación inmediata existente entre el infortunio y la actividad laboral desempeñada por el afiliado.

De lo expresado por los autores, se deduce que esta relación científica y legalmente reconocida entre la enfermedad y las condiciones en las cuales desarrollan los trabajadores sus actividades laborales será objeto de verificación por parte de los funcionarios del área de riesgos del trabajo del IESS; determinación que es necesaria, antes de otorgar las prestaciones correspondientes, puesto que se descartaría cualquier tipo de engaño a la institución. Como siguiente paso, se ilustrará el estudio con una lista no taxativa de enfermedades profesionales, en virtud de que fuera de ellas están las reconocidas por la Subdirección Nacional de Gestión y Control de Riesgos del Trabajo.

TABLA 2. Resumen de las enfermedades que, a efectos del Seguro General de Riesgos del Trabajo, se consideran profesionales

\begin{tabular}{|l|l|}
\hline $\begin{array}{c}\text { 1. Enfermedades profesionales según } \\
\text { el órgano o sistema afectado. }\end{array}$ & $\begin{array}{l}\text { Enfermedades del sistema osteomuscular: sín- } \\
\text { drome del túnel carpiano, tenosinovitis crónica } \\
\text { de la mano y bursitis prerrotuliana. }\end{array}$ \\
\hline 2. Otras enfermedades. & $\begin{array}{l}\text { Enfermedades que, a pesar de no constar en la } \\
\text { lista, se ha podido verificar el nexo que existe } \\
\text { entre la actividad laboral y la enfermedad con- } \\
\text { traída por el trabajador. }\end{array}$ \\
\hline
\end{tabular}

FUENTE: elaboración propia con datos de: Ecuador IESS, Reglamento del Seguro General de Riesgos del Trabajo, Registro Oficial 632, Edición Especial, 12 de julio de 2016, anexo 1.

En definitiva, tanto el accidente de trabajo como la enfermedad profesional conllevan consecuencias dañinas para el organismo de los afectados. Ahora bien, estos efectos conforme lo indica la normativa interna del IESS, se

42 Idem. 
clasifican en "a) Incapacidad Temporal; b) Incapacidad Permanente Parcial; c) Incapacidad Permanente Total; d) Incapacidad Permanente Absoluta; y, e) Muerte". ${ }^{43}$ Frente a ello, el Instituto Ecuatoriano de Seguridad Social, a través del departamento de riesgos del trabajo, otorga al afiliado prestaciones económicas que dependen del grado de incapacidad (subsidio, pensión e indemnización); atención médica, rehabilitación física, prótesis, etcétera. Además, en caso de muerte, el IESS otorgará a los deudos (hijos hasta que legalmente sean considerados mayores de edad y al cónyuge supérstite, quien perderá el derecho al contraer segundas nupcias o que legalmente se haya reconocido unión de hecho) una pensión mensual denominada montepío y, por último, contribuirá con los gastos del funeral (auxilio de funerales).

Por último, los sujetos a quienes la Resolución núm. CD 513 (Reglamento del Seguro General de Riesgos del Trabajo), ampara frente a un accidente de trabajo o enfermedad profesional, lo siguiente:

... el trabajador en relación de dependencia... el trabajador afiliado sin relación de dependencia o autónomo, independiente o por cuenta propia, el menor trabajador, y los demás asegurados... al régimen del Seguro General Obligatorio en virtud de leyes y decretos especiales y que cotice para este Seguro. ${ }^{44}$

En concordancia con el principio de universalidad y lo dispuesto por la Constitución y la Ley Orgánica para la Justicia Laboral y Reconocimiento del Trabajo en el Hogar, se entendería que en este grupo se encuentran incluidas las personas que realizan labores de autosustento y cuidado humano en sus hogares.

Sin embargo, del contenido de la citada Resolución núm. CD 513, se desprende una condición que limita el derecho a la seguridad social de las personas que realizan trabajo no remunerado del hogar, y es que del total del respectivo monto aportado al Seguro General Obligatorio, se desprenda un porcentaje destinado al Seguro General de Riesgos del Trabajo, tomando en consideración que este sector de la población afiliada no recibe ingresos mensuales, semanales o quincenales, ya que la actividad que realiza es reconocida como una forma de trabajo, pero no recibe remuneración alguna y que para

43 Ecuador, Resolución núm. C.D. 513. Registro Oficial 632, Edición Especial, 12 de julio de 2016, artículo 19.

44 Ibidem, artículo 3o. Énfasis añadido. 
su afiliación contribuyen económicamente el Estado y la Unidad Económica Familiar.

Para cerrar la idea, el Estado a través del Instituto Ecuatoriano de Seguridad Social (artículo 3o. del Reglamento del Seguro General de Riesgos del Trabajo), está transgrediendo el principio de progresividad y prohibición de regresividad de los derechos constitucionales, que consiste en que los derechos reconocidos tanto en la Constitución como en los tratados internacionales de derechos humanos, deberán ser desarrollados a través de la ley, la Constitución, las ordenanzas, las políticas públicas y la jurisprudencia, mas no se podrá limitar su contenido esencial.

\section{CONCLUSIONES}

$\mathrm{E}$ s plenamente posible evidenciar que la Constitución promueve la progresividad y a la vez prohíbe la regresividad en materia de derechos fundamentales; entre ellos, la seguridad social. No obstante, existe normativa jerárquicamente inferior a ella, como en el caso del Reglamento del Seguro General de Riesgos del Trabajo, que en su artículo 3o. contiene una condición que limita el derecho a la seguridad social a las personas que realizan trabajo no remunerado del hogar; quienes al no contar con ingresos, con mayor razón debería ponerse en práctica el principio de solidaridad (en conjunto con el principio de equidad en el gasto público); y así, quienes mayor cantidad de recursos tienen, contribuirán en mayor medida al sistema de seguridad social, colaborando para que toda la sociedad esté amparada en las mejores condiciones posibles.

En razón de que toda disposición que es contraria a la Constitución se presume inconstitucional, el artículo 3o. del citado Reglamento, es inconstitucional. En este sentido, lo que se recomienda es la reforma de este artículo, eliminando de su contenido la frase que vulnera derechos y que es: que cotice para este seguro.

\section{BiBLIOGRAFÍA}

Ávila SANTAmaría, Ramiro, "Caracterización de la Constitución de 2008: visión panorámica de la Constitución a partir del Estado constitucional de derechos y justicia", en ANDRADE, Santiago et al. (coords.), La nueva Cons- 
titución del Ecuador: Estado, derechos e instituciones, Quito, Universidad Andina Simón Bolívar-Corporación Editora Nacional, 2009.

CENTRO Interdisciplinario de Estudios sobre el Desarrollo Latinoamericano, La seguridad social en Latinoamérica: un estudio comparativo del seguro social en Argentina y Colombia, Buenos Aires, CIEDLA, 1989.

BENAVIDES, Fernando et al., "Trabajo y salud", Salud laboral. Conceptos y técnicas para la prevención de riesgos laborales, Barcelona, Elsevier-Masson, 2007.

Giuliani Fonrouge, Carlos, Derecho financiero, 3a. ed., Buenos Aires, Depalma, 1984.

Goñalons Benavent, Anna, "Patología del trabajo", en Moreno Cáliz, Susana (coord.), Manual de prevención de riesgos laborales (seguridad, higiene y salud en el trabajo), Barcelona, Atelier-Librería Jurídica Cevallos, 2012

INSTITUTO Ecuatoriano de Seguridad Social, Manualpara afiliados y empleadores del Instituto Ecuatoriano de Seguridad Social, Quito, IESS, 1984.

INSTITUTO Ecuatoriano de Seguridad Social, Valuación financiera actuarial para la protección del seguro general obligatorio a las personas que realicen trabajo en el hogar no remunerado, Quito, IESS, 2015.

MYERS, Robert, "Demografía y seguridad social”, Seguridad social y población, Washington, OEA, 1969.

Patiño Ledesma, Rodrigo y Pozo, Teodoro, Léxico Jurídico Tributario, Quito, CLD, 1996.

PÉrez Luño, Antonio, Los derechos fundamentales, Madrid, Tecnos, 1986.

PÉREZ RoYo, Fernando, "Ingresos tributarios de la seguridad social”, Curso de derecho tributario parte especial. Sistema tributario: los tributos en particular, Madrid, Marcial Pons, Ediciones Jurídicas y Sociales, 2002.

PORRAS Velasco, Angélica, "La seguridad social en Ecuador: un necesario cambio de paradigmas", Foro Revista de Derecho, núm. 24, 2015.

PRIETO SANCHÍs, Luis, "Los derechos sociales y el principio de igualdad sustancial”, en CAicedo TAPia, Danilo y Porras Velasco, Angélica (eds.), Igualdad y no discriminación: el reto de la diversidad, Quito, Ministerio de Justicia, Derechos Humanos y Cultos, 2010.

ProAÑo MAYA, Marco, Seguridad social y sociedad democrática, Quito, Editorial Americana, 2014.

RENDÓN VÁSQUEZ, Jorge, Derecho de la seguridad social, Lima, Grijley, 2008. 
RODRíGUEZ Y RODRíGUEZ, Jesús y CARBONELl, Miguel, voz: "Derechos humanos", Diccionario de derecho constitucional, México, Porrúa-UNAM, 2009.

RODRíGUEZ MESA, Rafael, Estudios sobre seguridad social, Barranquilla, Universidad del Norte-Grupo Editorial Ibáñez, 2012.

RuIZ, José Mario, La formación del concepto de seguridad social, Quito, Casa de la Cultura Ecuatoriana, 1961. 